\title{
Anaesthesia for total hip and knee replacement: A review of patient education materials available online [version 1; peer
} review: 2 approved]

\author{
Rebecca Marshall(D1, Eoghan Pomeroy², Catriona McKendry², Michael Gilmartin²,

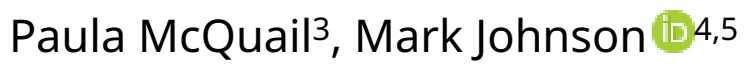

\footnotetext{
${ }^{1}$ Department of Anaesthesia, University Hospital Galway, Galway, Connaght, H91 YR71, Ireland

${ }^{2}$ Department of Orthopaedics, Mater Misericordiae University Hospital, Dublin, Dublin, Ireland

${ }^{3}$ Department of Orthopaedics, St. James's Hospital, Dublin, Dublin, Ireland

${ }^{4}$ School of Medicine, University College Dublin, Dublin, Ireland

${ }^{5}$ Department of Anaesthesia, Fiona Stanley Hospital, Murdoch, Australia
}

V1 First published: 09 Apr 2019, 8:416

https://doi.org/10.12688/f1000research.18675.1

Latest published: 09 Apr 2019, 8:416

https://doi.org/10.12688/f1000research.18675.1

\section{Abstract}

Background: Patients frequently consult the internet for health information. Our aim was to perform an Internet-based readability and quality control study using recognised quality scoring systems to assess the patient information available online relating to anaesthesia for total hip and knee replacement surgery.

Methods: Online patient information relating to anaesthesia for total hip and knee replacement was identified using Google, Bing and Yahoo with search terms 'hip replacement anaesthetic', 'knee replacement anaesthetic.' Readability was assessed using Flesch Reading Ease (FRE), Flesch-Kincaid grade level (FKGL) and Gunning Fog Index (GFI). Quality was assessed using DISCERN instrument, Health On the Net Foundation seal, and Information Standard mark.

Results: 32 websites were analysed. $25 \%$ were HONcode certified, $15.6 \%$ had the Information Standard. Mean FRE was 55.2 \pm 12.8 . Mean FKGL was $8.6 \pm 1.9$. Six websites $(18.8 \%)$ had the recommended $6^{\text {th }}$. grade readability level. Mean of $10.4 \pm 2.6$ years of formal education was required to read the websites. Websites with Information Standard were easier to read: FKGL (6.2 vs. $9, P<0.001)$, GFI ( 8.8 vs. $10.7, P=0.04)$, FRE score (64.2 vs. $9, P=0.02)$. Mean DISCERN score was low: $40.3 \pm 13$.

Conclusions: Overall, most websites were poor quality with reading levels too high for the target audience. Information Standard NHS quality mark was associated with improved readability, however along with HONcode were not found to have a statistically significant correlation with quality. Based on this study, we would encourage healthcare professionals to be judicious in the websites they recommend to patients, and to consider both the readability and

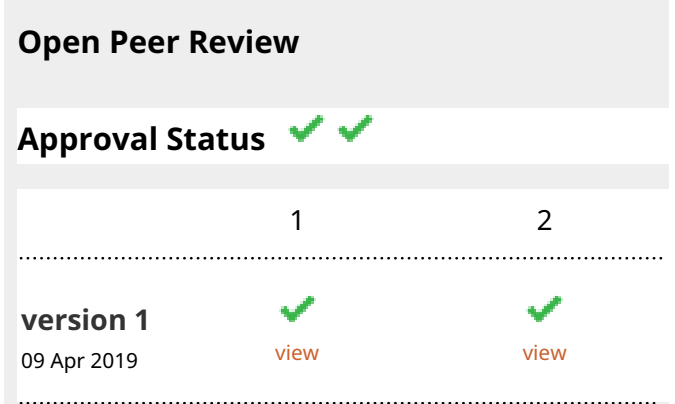

1. Thomas W Wainwright $\mathrm{ID}$, Bournemouth

University, Bournemouth, UK

Louise Burgess (D), Bournemouth

University, Bournemouth, UK

2. John McNamara, University College Cork, Cork, Ireland

Any reports and responses or comments on the article can be found at the end of the article. 
quality of the information provided.

Keywords

Anaesthesia, Quality, Readability, Total knee replacement, Total hip replacement, Internet, Patient information.

Corresponding author: Rebecca Marshall (marshall.rebecca38@gmail.com)

Author roles: Marshall R: Conceptualization, Data Curation, Investigation, Methodology, Visualization, Writing - Original Draft Preparation, Writing - Review \& Editing; Pomeroy E: Data Curation, Investigation, Writing - Review \& Editing; McKendry C: Formal Analysis; Gilmartin M: Writing - Review \& Editing; McQuail P: Writing - Review \& Editing; Johnson M: Supervision, Writing - Review \& Editing

Competing interests: No competing interests were disclosed.

Grant information: The author(s) declared that no grants were involved in supporting this work.

Copyright: $\odot 2019$ Marshall R et al. This is an open access article distributed under the terms of the Creative Commons Attribution License, which permits unrestricted use, distribution, and reproduction in any medium, provided the original work is properly cited.

How to cite this article: Marshall R, Pomeroy E, McKendry C et al. Anaesthesia for total hip and knee replacement: A review of patient education materials available online [version 1; peer review: 2 approved] F1000Research 2019, 8:416 https://doi.org/10.12688/f1000research.18675.1

First published: 09 Apr 2019, 8:416 https://doi.org/10.12688/f1000research.18675.1 


\section{Introduction}

Total hip replacement (THR) and total knee replacement (TKR) are proven interventions for patients with advanced arthritis, and are among the most common elective surgical procedures carried out in the UK and Ireland ${ }^{1}$. National Joint Registry data for both the UK and Ireland reveals that close to 200,000 total hip and knee replacements are performed each year ${ }^{2,3}$. Demand for both THR and TKR is set to increase dramatically in the coming decades due to changing demographics and an ageing population, with studies suggesting the demand for TKR in the United States will grow by $673 \%$ by $2030^{4-6}$. Anaesthesia can play a significant role in reducing perioperative morbidity, and in an increasingly complex patient population it is important that patients are given accurate and up to date information about the various anaesthetic techniques used ${ }^{7}$.

Internet use is increasing worldwide, with $85 \%$ of adults in the United States using the Internet ${ }^{8}$. In the UK, the Oxford Internet Survey group stated that in $2013,78 \%$ of people used the Internet and, of these, up to $71 \%$ sought health related information". Patient education materials (PEM) can be beneficial for assisting patients in the informed consent procedure, by explaining indications, risks, benefits and alternatives ${ }^{10}$. A recent online poll revealed that up to $90 \%$ of patients who access the Internet for their health information believe it to be accurate, and over $60 \%$ reported that it impacted their medical decision making ${ }^{11}$. However, the Internet is a completely unregulated source susceptible to provider bias and has the capacity to negatively influence consumer health outcomes ${ }^{12}$. Implementing and enforcing standards is very difficult, and health information available has been shown to be of poor quality and largely unreliable $e^{8,11,13,14}$. It is important for doctors to be aware of the information available to patients on the Internet and to understand confusion surrounding such information. As well as supplying high quality accurate health information, the readability of the website must be suitable for the target audience. Several medical organisations, including the National Institute of Health (NIH), and the American Medical Association (AMA) recommend that all PEM should be written at or below sixth grade level (reading age 11-12 years) in order to be effectively understood by the general public ${ }^{15}$. However many previous studies have shown that a significant proportion of health information websites are written above this recommended level, suggesting that it may be beyond the comprehension of a substantial proportion of the patient population accessing it 16-18.

Over the past number of years there has been several studies assessing both the quality and readability of PEM available on the Internet across all medical specialties, including general and regional anaesthesia for labour and pain procedures ${ }^{19-22}$. We also already know that orthopaedic patients research their conditions extensively online $e^{11,13,23,24}$, but to our knowledge none of these studies have looked at the availability of high quality health information relating to anaesthesia for common surgical procedures. Therefore, our aim was to assess the readability and quality of patient information available on the Internet relating to anaesthesia for both TKR and THR.

\section{Methods}

Ethics

According to the policy activities that constitute research at the institute in question, this work met criteria exempt from ethics review.

\section{Search engines}

On 26/09/2017 the search terms 'hip replacement anaesthetic' and 'knee replacement anaesthetic' were entered into the top three most commonly used search engines for 2017: Google, Bing and Yahoo. Most Internet users do not go beyond the first three pages of returned searches ${ }^{22}$, so we only included those websites in the analysis; 27 sites for each of the above terms on both Google and Bing ( 9 websites per page) and 30 for each on Yahoo (10 websites per page), giving a total of 168 . Websites were then excluded from further analysis if they were not PEM, if they were written in a language other than English, if they were inaccessible, or in a non-written format, i.e. video. Duplicate websites were also excluded. In total 32 unique websites were identified for examination, as shown in Table 1.

\section{Scoring systems}

Website authorship was determined independently by close examination by the first two authors (R.M, E.P.) and each one was placed in one of the following categories: 1) physician, author or authors were individual or group physicians with no university or research group; 2) academic, author or authors were affiliated with a university or research group; 3) commercial site, author or authors were marketing a product related to the subject; 4) commercial/physician, author or authors were individual or group physicians also marketing a product related to the subject; 6) Government/Not for profit organisations (NPO), author or authors were affiliated with a government or registered charity; 7) media-related, author or authors affiliated with the media; and 7) social/discussion, to reflect the growing trend of the use of these modalities to distribute information ${ }^{12}$.

\section{Readability}

The readability of a text is determined as the education level a person completed to understand the written material, based on the US reading grade level ${ }^{10}$. We assessed the readability of each website using three validated, commonly used readability assessment tools: the Flesch Reading Ease (FRE) score, the Flesch-Kincaid grade level (FKGL), and the Gunning Fog Index (GFI). The FRE score generates a score between 0-100, using the formula: 206.835 - 1.015(total words/total sentences) 84.6(total syllables/total words). It is based on the total words, syllables and sentences in a written passage and a score $<60$ considers the document to be difficult to read by the general public $^{8,19}$. The FKGL corresponds to the US reading grade level and is calculated using the formula: 0.39(total words/total sentences $)+11.8$ (total syllables/total words) -15.59 . The GFI is calculated using the formula: 0.4 [(words/sentences) +100 (complex words/words), and estimates the number of years of formal education required to read a passage of text ${ }^{8}$. Readability scores for all PEM websites were generated using an online readability calculator. 


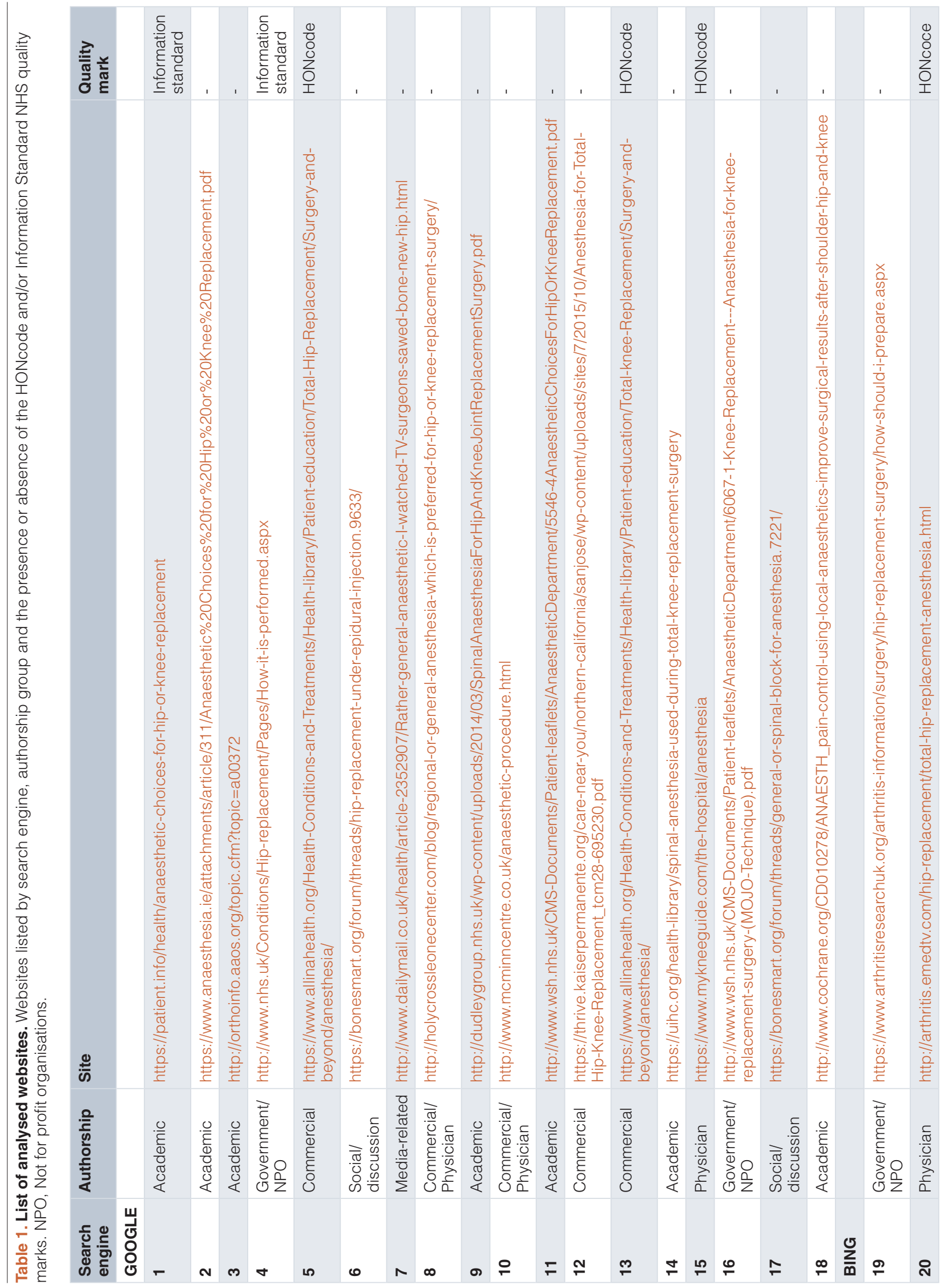




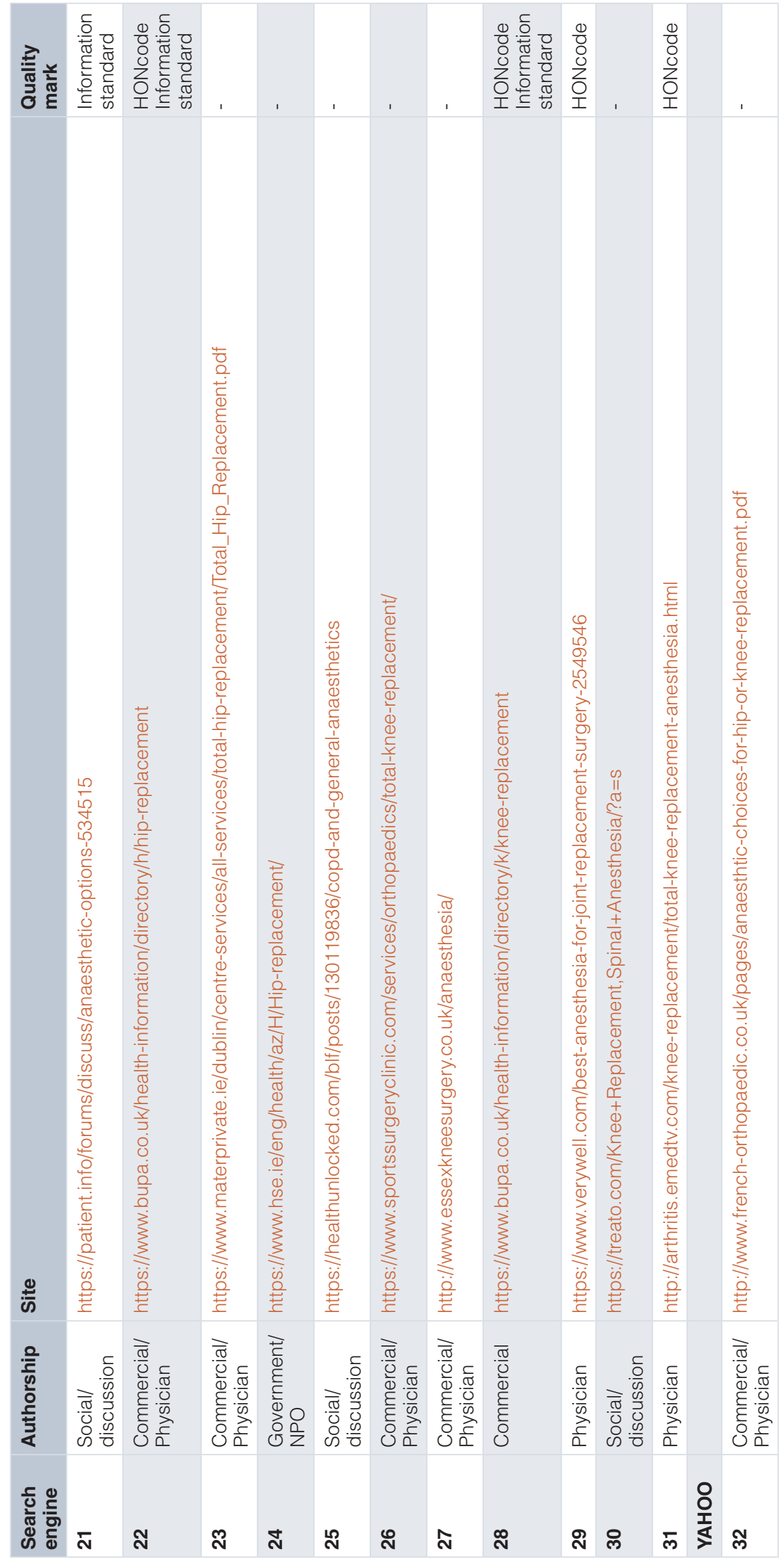


Quality

The quality of each website was assessed by the two authors using the DISCERN instrument, and according to the presence or absence of the Health On the Net (HON) Foundation seal and the Information Standard mark. The DISCERN instrument is a validated rating tool of the quality of health information developed by the NHS Executive Research and Development Programme. It consists of 15 key questions plus an overall quality rating and generates a score between 80 (highest) and 16 (lowest), a lower score being reflective of a website that is of poor quality information on treatment choices ${ }^{25}$. The HON Foundation criteria was developed in 1995 by a non-profit, non-governmental organisation, accredited to the Economic and Social Council of the United Nations, in an attempt to improve the quality of internet-based health information. The HON Foundation provides a code of conduct seal for websites that meet its quality and reliability standards ${ }^{8,14}$. The Information Standard quality mark was established by the UK Department of Health to help patients and the public make informed choices about their lifestyle, condition and options for treatment and care. It is a certification scheme for health and social care information, which indicates that an organisation is a reliable source of health and social care information.

\section{Statistical analysis}

Calculations were performed using SPSS version 23 (SPSS, Inc., Armonk, NY). Mean scores and standard deviation are presented for normally distributed variables. Median values and standard deviation are presented for non-normally distributed data. One-way ANOVA/Independent samples Kruskal-Wallis Test were used as appropriate in intergroup comparisons. In comparisons between certified and noncertified groups, independent samples $\mathrm{T}$ test/Mann Whitney $\mathrm{U}$ test were applied as appropriate. Significance was set at $P<0.05$ for all studies.

\section{Results}

Out of the 168 initial search results, 32 were analysed further as per the previously described exclusion criteria (Figure 1). Each website was categorised according to authorship; seven were academic, seven were commercial/physician, five were discussion/social media related, four were physician, four were Government/NPO related, four were commercial and one was

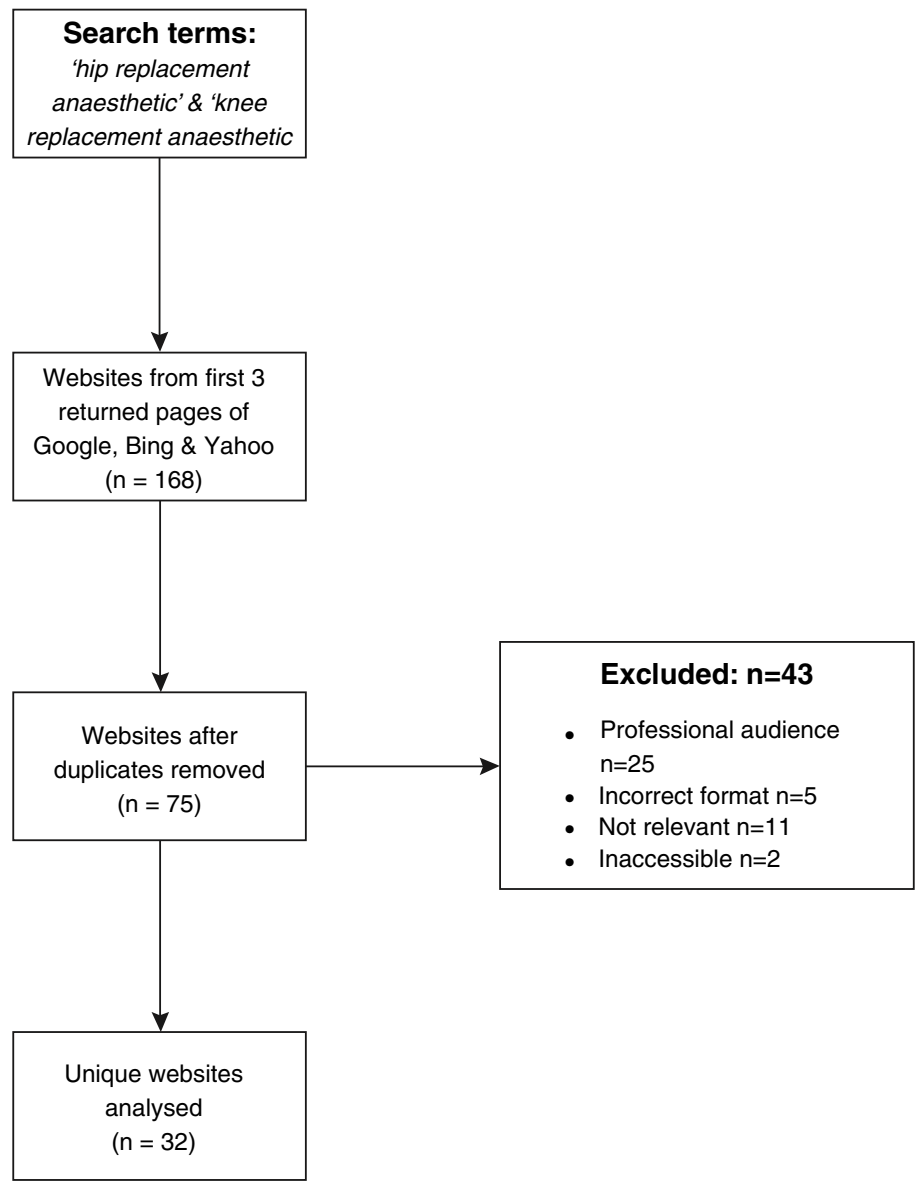

Figure 1. Results flow diagram of analysed websites. 27 sites for each of the above terms on both Google and Bing ( 9 websites per page) and 30 for each on Yahoo (10 websites per page), giving a total of 168. Websites were then excluded from further analysis if they were not PEM, if they were written in a language other than English, if they were inaccessible, or in a non-written format i.e. video. Duplicate websites were also excluded. In total 32 unique websites were analysed further. 
media-related (Figure 2). Only 8/32 sites (25\%) were HONcode certified and 5/32 (15.6\%) had the Information Standard quality mark.

\section{Readability}

The readability of each website was assessed using three validated commonly used readability assessment tools: the Flesch Reading
Ease (FRE) score, the Flesch-Kincaid grade level (FKGL), and the Gunning Fog Index (GFI). Table 2 summarises the study's readability and quality scores. The overall mean readability scores indicated that the websites as a group were difficult to read. The mean FRE score was $55.2 \pm 12.8$, with social/discussion networks associated with both the minimum (3.3) and maximum (74.2) FRE scores. The mean FKGL score was $8.6 \pm 1.9$, with only

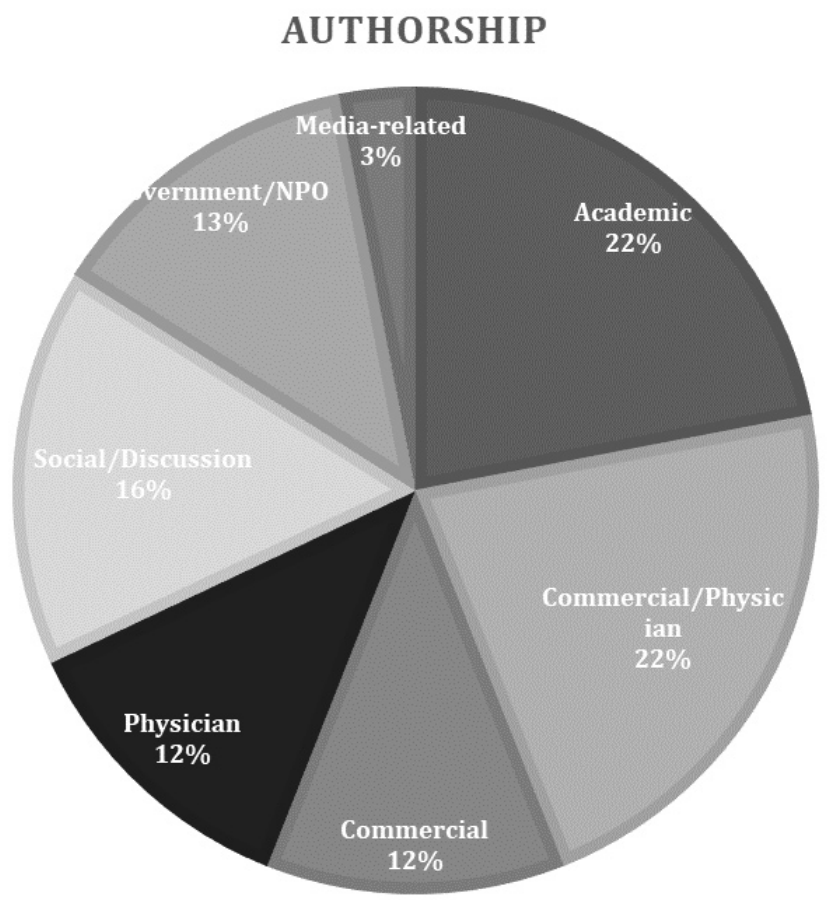

Figure 2. Each website was categorised according to authorship. Seven were academic, seven were commercial/physician, five were discussion/social media related, four were physician, four were Government/NPO related, four were commercial and one was mediarelated.

Table 2. Readability and quality values across all authorship groups. Overall results for each scoring system, presented as mean \pm standard deviation for normally distributed data and median \pm standard deviation for non-normally distributed data (FRE Score). FRE, Flesch Reading ease; FKGL, Flesch-Kincaid Grade Level; GFI, Gunning Fox Index; DISCERN, DISCERN instrument.

\begin{tabular}{|l|l|l|l|l|}
\hline & FRE Score & FKGL & GFI & DISCERN \\
\hline Total & $55.2 \pm 12.8$ & $8.6 \pm 1.9$ & $10.4 \pm 2.6$ & $40.3 \pm 13$ \\
\hline Academic & $54.8 \pm 7.1$ & $8.6 \pm 1$ & $10.6 \pm 2.1$ & $49.7 \pm 11.8$ \\
\hline Commercial/physician & $55.9 \pm 8.0$ & $8.7 \pm 1.4$ & $10.9 \pm 1.7$ & $38 \pm 14.3$ \\
\hline Commercial & $51.8 \pm 8.3$ & $8.5 \pm 1.8$ & $11.7 \pm 2.3$ & $43 \pm 6.7$ \\
\hline Physician & $46.6 \pm 3.6$ & $9.7 \pm 2.2$ & $11.4 \pm 3.2$ & $47.8 \pm 6.8$ \\
\hline Social/discussion & $70.1 \pm 30.1$ & $8.5 \pm 3.6$ & $8.3 \pm 3.9$ & $24.8 \pm 3.4$ \\
\hline Government/ Not for profit organisations & $56.5 \pm 4.6$ & $7.6 \pm 1.9$ & $10.1 \pm 2.1$ & $41.8 \pm 10.8$ \\
\hline Media-related & $\mathrm{N} / \mathrm{A}$ & $\mathrm{N} / \mathrm{A}$ & $\mathrm{N} / \mathrm{A}$ & $\mathrm{N} / \mathrm{A}$ \\
\hline HON-code + & $51.2 \pm 8.1$ & $8.5 \pm 2.1$ & $10.8 \pm 2.4$ & $45.4 \pm 6.7$ \\
\hline HON-code - & $56.4 \pm 14.1$ & $8.6 \pm 1.9$ & $10.3 \pm 2.7$ & $38.5 \pm 14.2$ \\
\hline Information Standard + & $64.2 \pm 5.4$ & $6.2 \pm .8$ & $8.8 \pm 1.2$ & $42.4 \pm 12.6$ \\
\hline Information Standard - & $51.9 \pm 13$ & $9.0 \pm 1.7$ & $10.7 \pm 2.7$ & $39.9 \pm 13.3$ \\
\hline
\end{tabular}


six websites (18.8\%) having the recommended readability level of sixth-grade or less (Figure 3). Overall, a mean of 10.4 years (mean GFI $10.4 \pm 2.6$ ) of formal education was required to read the websites included in this study. Commercial websites had the highest mean GFI (11.7 \pm 2.3$)$, while social/discussion networks had the lowest $(8.3 \pm 3.9)$.

Organisations that have achieved the Information Standard quality mark were as a group easier to read. This was seen across all three readability assessment tools. Member websites had a significantly lower mean FKGL $(6.2$ vs. $9, P<0.001)$ and GFI $(8.8$ vs. $10.7, P=0.04)$ and a significantly higher median FRE score (64.2 vs. $9, P=0.02)$ than non-member websites. There was no difference in FKGL (8.5 vs. 8.6, $P=0.78$ ), GFI (10.8 vs. 10.3, $P=0.92)$ or FRE (51.2 vs. $56.4, P=0.31$ ) between HONcode certified and noncertified groups.

\section{DISCERN Instrument}

The DISCERN instrument was used to assess each website. Overall, the mean DISCERN score was low, $40.3 \pm 13$ out of a maximum of 80 . Three of the top five scoring websites were of academic authorship with one being of physician authorship and one Government/NPO. Eight websites (25\%) scored 51 or above, representing good quality, with academic authorship associated with both the single highest DISCERN score (61) and the highest mean DISCERN score across all groups (49.7). Six websites $(18.75 \%)$ scored less than 26 points, representing very poor quality with extensive shortcomings. Average DISCERN scores by authorship groups are shown in Figure 4. Neither
HONcode nor the presence of the Information Standard quality mark was associated with a higher mean DISCERN score ( $P=0.08$ and $P=0.7$, respectively). Academic and physicianrelated websites achieved significantly higher mean DISCERN scores than social/discussion networks $(P=0.005$ and $P=0.032$, respectively; Figure 5).

\section{Discussion}

There can be no doubt that the Internet has changed the manner in which patients access information. Traditionally, information was passed from doctor to patient in a single direction and decisions were made under the paternalistic guidance of the doctor. In the Internet era, in which information is immediately available, this flow of information is no longer appropriate, nor is it acceptable to patients. More and more, patients are accessing this medical information online and using it to make decisions regarding their own healthcare ${ }^{8,18}$. However, the reliability and suitability of these online patient education materials is increasingly being called into question ${ }^{8,13,14,16-18}$. The majority of Internet users start their search with a search engine, and most do not trawl beyond the websites from the first three pages returned ${ }^{22}$. The aim of this study was to assess both the quality and the readability of Internet information relating to anaesthesia for total hip replacement and total knee replacement, using three validated tools to assess readability (FRE, GFI, FKGL) and the DISCERN instrument to assess quality of information obtained. We also looked for websites that displayed HONcode certification or had received the Information Standard NHS quality mark.

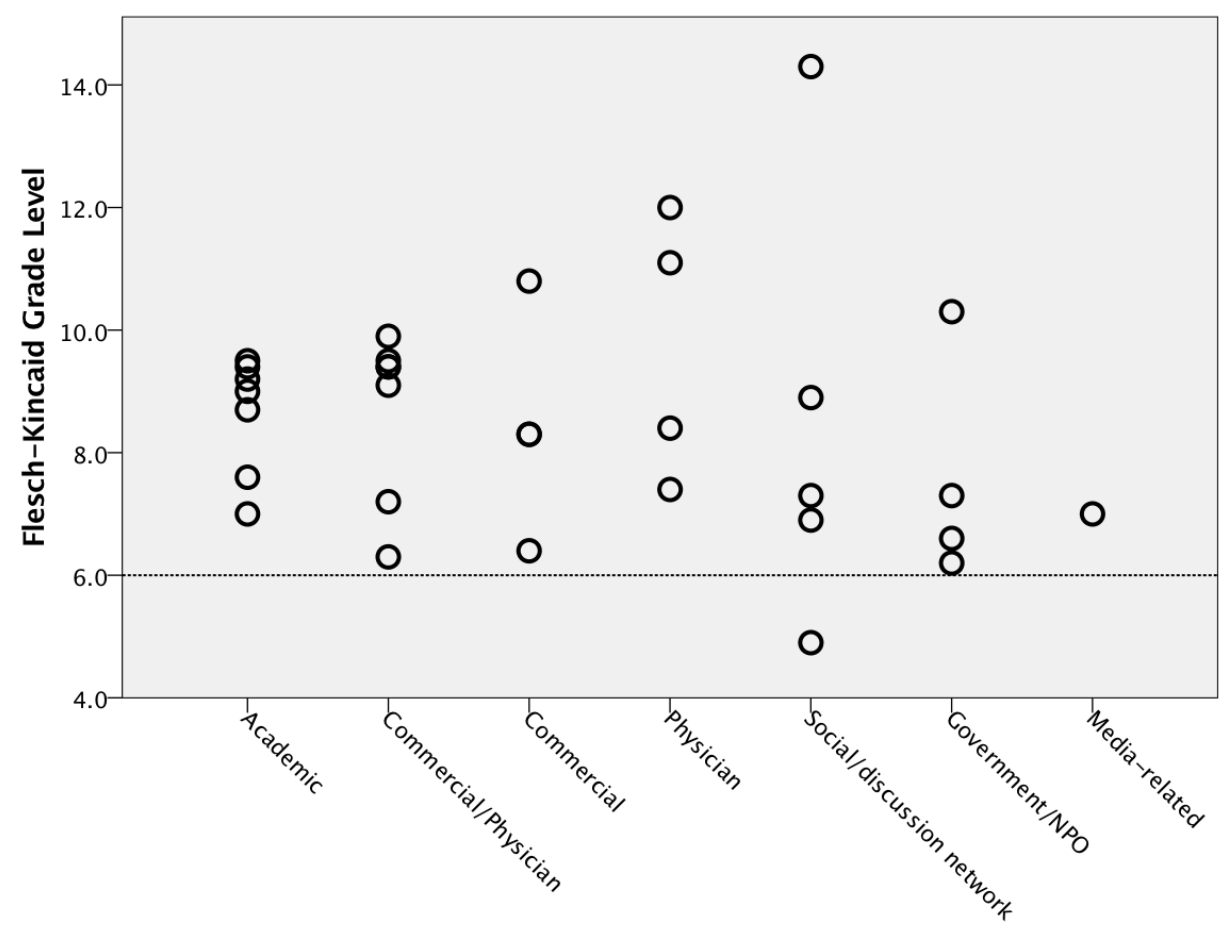

Author

Figure 3. Flesch-Kincaid Grade Level by authorship. The line denotes the recommended readability level of the sixth-grade level with a minority of websites falling at or below this level. 


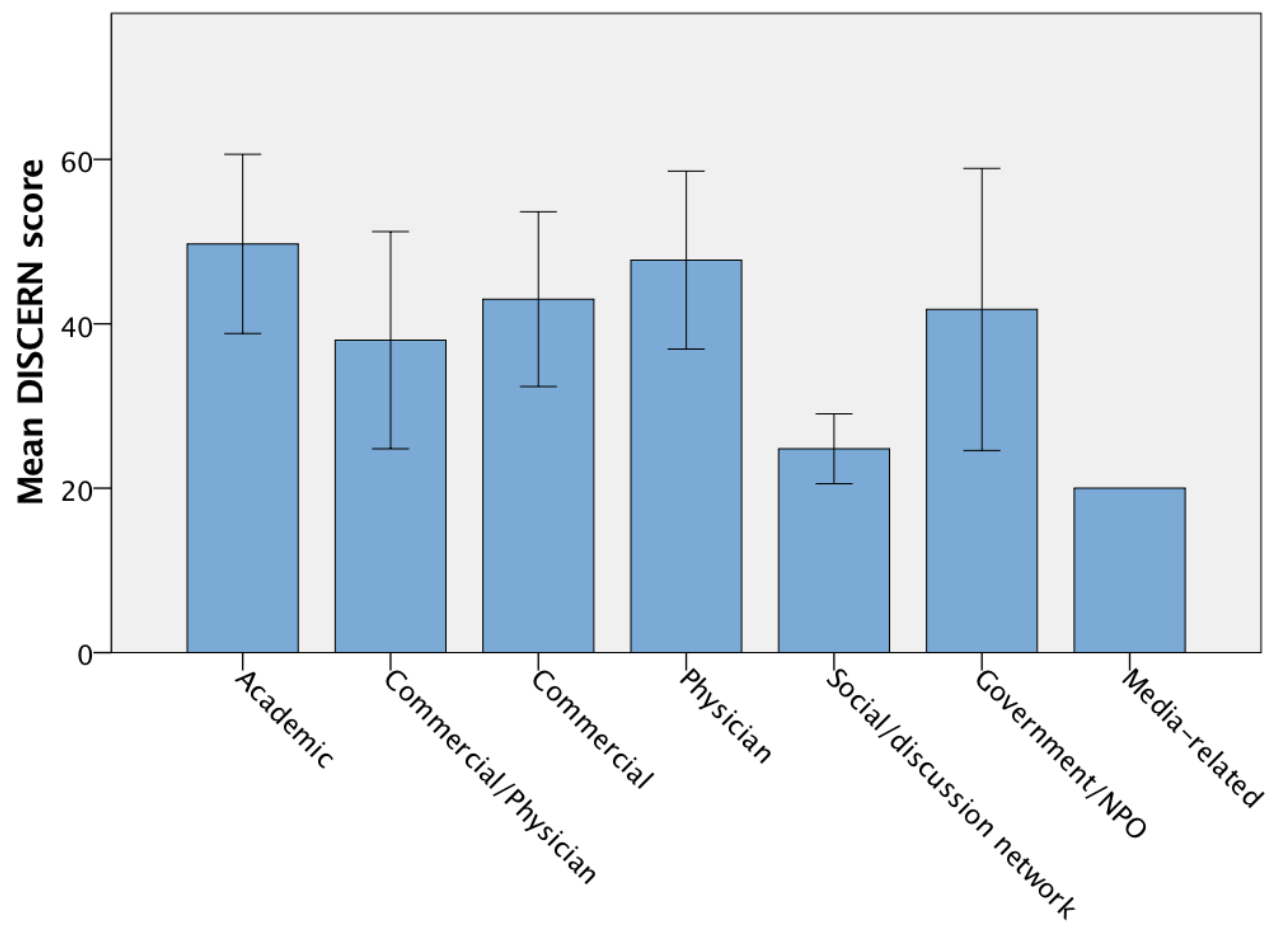

Author

Figure 4. Bar chart of DISCERN scores by authorship. From highest (61) to lowest (20) mean DISCERN score. Error bars denote 95\% confidence interval

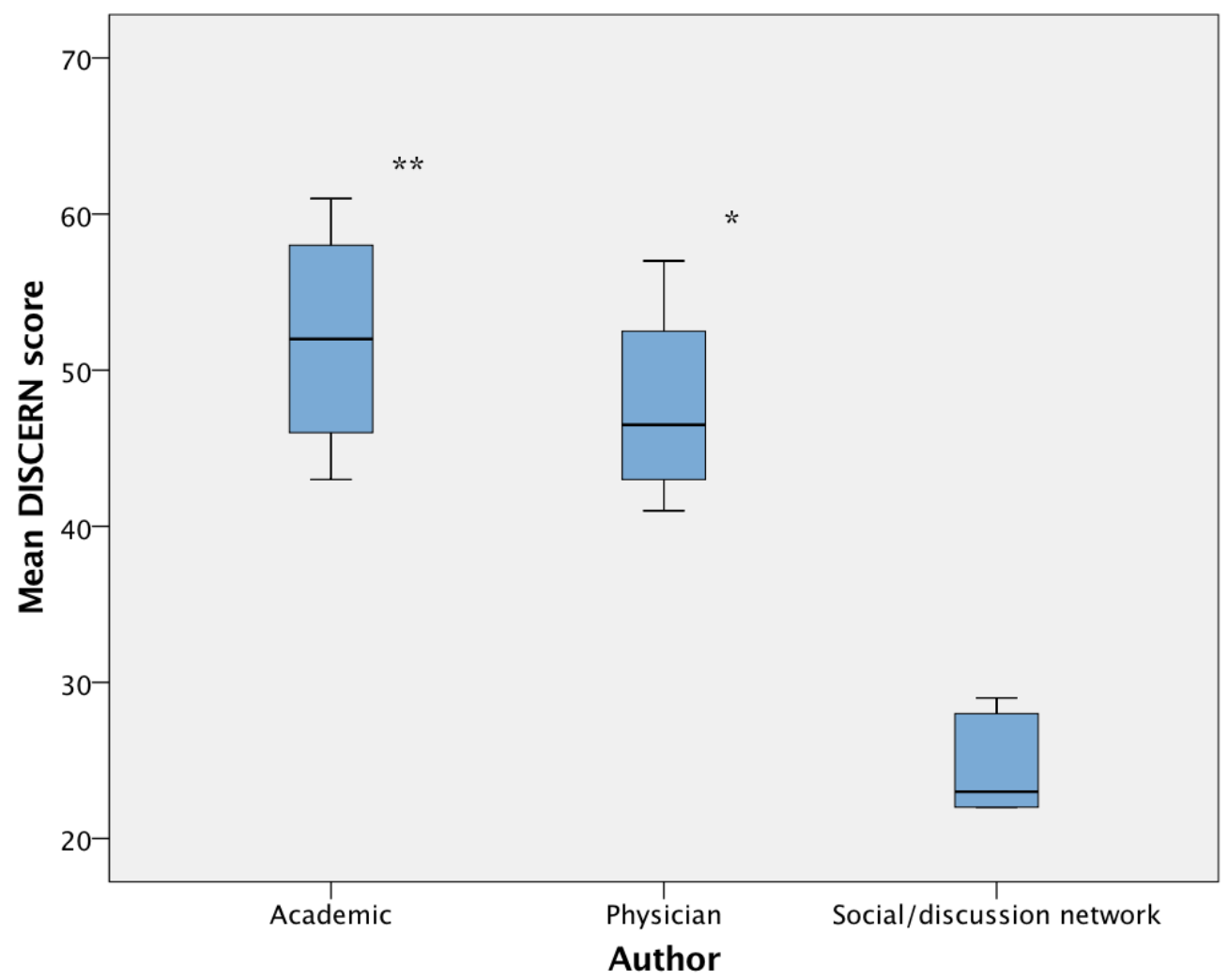

Figure 5. Mean DISCERN scores. Significantly higher for academic $(P=0.005)$ and physician-related $(P=0.032)$ websites versus the mean DISCERN score for social/discussion networks. 
Our results show that $81.2 \%$ of the websites assessed were above the recommended sixth-grade readability level for PEM. This should be a concern for healthcare providers; many patients will have a limited understanding of the health information available to them online, and thus even those patient education materials that may be of good quality may not be understood. This could have an adverse effect on the informed consent and decision-making process. These findings echo multiple studies over the last decade, suggesting that producing information at an appropriate readability level is still a challenge for healthcare providers $^{10,18,19,21}$. Encouragingly, our study found that websites that had been awarded the Information Standard NHS quality mark were statistically significantly more likely to achieve the appropriate readability level, suggesting that these are the websites that healthcare providers should be recommending to our patients.

The quality of the websites was assessed using the DISCERN instrument. It is important to note that the DISCERN instrument does not take into account the readability of the material, and thus when recommending websites to patients, healthcare providers should seek websites which are of both high quality and appropriate readability. In our study, only a small number of the websites analysed (25\%) scored highly using the DISCERN instrument, which indicates that most PEM related to anaesthesia for TKR and THR available on the Internet are of poor quality. Websites were more likely to achieve high DISCERN scores if the authors were physicians, affiliated with academic institutions or government agencies. Again, this highlights the importance of healthcare professionals directing patients towards more reliable and appropriate PEM.

One of the most significant and disappointing findings from our study relates to the presence or absence of the HONcode seal on websites. Although the HONcode seal indicates that a website has met certain quality and reliability standards, our study did not find that HONcode certified websites achieved higher readability or quality standards than those without the HONcode seal. The Information Standard quality mark was introduced to help patients make informed choices about their condition and options for treatment. In our study, we found that although there was a statistically significant relationship between the presence of the Information Standard quality mark and appropriate reading levels, there was no correlation between this quality mark and quality of information using the DISCERN instrument.

A number of limitations to this study are recognised. We performed our online search in one country, and only analysed PEM from websites written in the English language. The search was limited to the first three pages of returned websites, as it has been shown previously that the general public usually don't pursue beyond this ${ }^{22}$. We acknowledge that comprehension of healthcare information is not solely related to readability of text and that other factors, i.e. videos and visual tools, can contribute greatly to a patient's understanding. The examination of such materials was beyond the scope of this study and previous studies have also acknowledged this limitation ${ }^{8,16}$. While readability indices have been validated in the literature, there is no general consensus on which index is best and each one uses a different formula to calculate readability. Scores by different indices may vary substantially. It should also be noted that although there is a large volume of material available to guide users when appraising websites using the DISCERN instrument, there is still the potential for variability among raters, which is a limitation not present when assessing readability.

In conclusion, we aimed to assess the quality and readability of information available online regarding anaesthesia for total knee replacement and total hip replacement. Overall, we found that most of the websites were of poor quality and many had reading levels which were too high for the target audience. These findings echo many other studies that examine online information relating to healthcare ${ }^{8,11,13,16,17,19,20}$. We found that while the Information Standard NHS quality mark was associated with improved readability, neither the quality mark nor the HONcode were found to have a statistically significant correlation with quality of material. Based on this study we would encourage doctors and other healthcare professionals to be judicious in the websites they recommend to patients, and to consider both the readability and the quality of the information provided.

\section{Data availability}

\section{Underlying data}

Figshare. WorkbookFinalPEM.xlsx. Data figures relating to an internet-based readability and quality control study using recognised quality scoring systems to assess the patient information available online for anaesthesia for total hip and knee replacement surgery. https://doi.org/10.6084/m9.figshare. 7940753.v126.

Data are available under the terms of the Creative Commons Attribution 4.0 International license (CC-BY 4.0).

\section{Grant information}

The author(s) declared that no grants were involved in supporting this work.
1. Culliford D, Maskell J, Judge A, et al.: Future projections of total hip and knee arthroplasty in the UK: results from the UK Clinical Practice Research Datalink. Osteoarthritis Cartilage. 2015; 23(4): 594-600. PubMed Abstract | Publisher Full Text

2. O'Neill BJ, Nugent M, Cashman JP, et al:: The Irish National Joint Registry: where are we now? Ir J Med Sci. 2014; 183(1): 77-83. PubMed Abstract | Publisher Full Text
3. The NJR Editorial Board: 2017 14th Annual Report: National Joint Registry for England, Wales, Northern Ireland and the Isle of Man. Surgical data to 31 December 2016. National Joint Registry; 2017. Reference Source

4. Galbraith JG, Fenelon C, Gibbons J, et al:: Enhanced recovery in lower limb arthroplasty in the Irish setting. Ir J Med Sci. 2017; 186(3): 687-91. PubMed Abstract | Publisher Full Text 
5. Johnson RL, Kopp SL, Burkle CM, et al.: Neuraxial vs general anaesthesia for total hip and total knee arthroplasty: a systematic review of comparativeeffectiveness research. Br J Anaesth. 2016; 116(2): 163-76.

PubMed Abstract | Publisher Full Text

6. Patel A, Pavlou G, Mújica-Mota RE, et al:: The epidemiology of revision total knee and hip arthroplasty in England and Wales: a comparative analysis with projections for the United States. A study using the National Joint Registry dataset. Bone Joint J. 2015; 97-B(8): 1076-81.

PubMed Abstract | Publisher Full Text

7. Grant CRK, Checketts MR: Analgesia for primary hip and knee arthroplasty: the role of regional anaesthesia. Continuing Education in Anaesthesia, Critical Care Pain. 2008; 8(2): 56-61.

Publisher Full Text

8. O'Neill SC, Baker JF, Fitzgerald C, et al:: Cauda equina syndrome: assessing the readability and quality of patient information on the Internet. Spine (Phila Pa 1976). 2014; 39(10): E645-9.

PubMed Abstract | Publisher Full Text

9. Dutton W, Blank G, Groselj D: Cultures of the Internet: The Internet in Britain. Oxford Internet Survey 2013 Report. [Internet]. Oxford: Oxford Internet Institute; 2013 [cited 2017 Oct 26]

Reference Source

10. De Oliveira GS, Jung M, Mccaffery KJ, et al.: Readability evaluation of Internetbased patient education materials related to the anesthesiology field. $J$ Clin Anesth. 2015; 27(5): 401-5.

PubMed Abstract | Publisher Full Text

11. Nason GJ, Baker JF, Byrne DP, et al:: Scoliosis-specific information on the internet: has the "information highway" led to better information provision? Spine (Phila Pa 1976). 2012; 37(21): E1364-9. PubMed Abstract | Publisher Full Text

12. Murray E, Lo B, Pollack L, et al:: The impact of health information on the Internet on health care and the physician-patient relationship: national U.S. survey among 1.050 U.S. physicians. J Med Internet Res. 2003; 5(3): e17. PubMed Abstract | Publisher Full Text | Free Full Text

13. Cassidy JT, Baker JF: Orthopaedic Patient Information on the World Wide Web: An Essential Review. J Bone Joint Surg Am. 2016; 98(4): 325-38. PubMed Abstract | Publisher Full Text

14. Elhassan $\mathrm{Y}$, Sheridan G, Nassiri M, et al:: Discectomy-related information on the internet: does the quality follow the surge? Spine (Phila Pa 1976). 2015; 40(2): $121-5$.

PubMed Abstract | Publisher Full Text

15. Weiss BD: Health literacy and patient safety: Help patients understand.
Manual for clinicians [Internet]. 2nd ed. Chicago: American Medical Association Foundation; 2007 [cited 2017 Oct 27].

Reference Source

16. Patel SK, Gordon EJ, Wong CA, et al.: Readability, Content, and Quality Assessment of Web-Based Patient Education Materials Addressing Neuraxia Labor Analgesia. Anesth Analg. 2015; 121(5): 1295-300. PubMed Abstract | Publisher Full Text

17. Kumar G, Howard SK, Kou A, et al:: Availability and Readability of Online Patient Education Materials Regarding Regional Anesthesia Techniques fo Perioperative Pain Management. Pain Med. 2017; 18(10): 2027-32. PubMed Abstract | Publisher Full Text

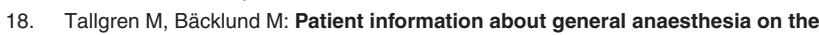
internet. Anaesthesia. 2009; 64(4): 408-15. PubMed Abstract | Publisher Full Text

19. Lynch NP, Lang B, Angelov S, et al.: Breast reconstruction post mastectomyLet's Google it. Accessibility, readability and quality of online information. Breast. 2017; 32: 126-9. PubMed Abstract | Publisher Full Text

20. Bailey MA, Coughlin PA, Sohrabi S, et al.: Quality and readability of online patient information for abdominal aortic aneurysms. J Vasc Surg. 2012; 56(1): 21-6. PubMed Abstract | Publisher Full Text

21. Ritchie L, Tornari C, Patel PM, et al: Glue ear: how good is the information on the World Wide Web? J Laryngol Otol. 2016; 130(2): 157-61. PubMed Abstract | Publisher Full Text

22. Hirsch M, Aggarwal S, Barker C, et al:: Googling endometriosis: a systematic review of information available on the Internet. Am J Obstet Gynecol. 2017: 216(5): 451-458.e1.

PubMed Abstract | Publisher Full Text

23. Crozier-Shaw G, Queally JM, Quinlan JF: Metal-on-Metal Total Hip Arthroplasty: Quality of Online Patient Information. Orthopedics. 2017; 40(2): e262-8. PubMed Abstract | Publisher Full Text

24. Mathur S, Shanti N, Brkaric M, et al:: Surfing for scoliosis: the quality of information available on the Internet. Spine (Phila Pa 1976). 2005; 30(23): 2695-700. PubMed Abstract | Publisher Full Text

25. Charnock D, Shepperd S: The DISCERN Handbook: Quality criteria for consumer health information on treatment choices [Internet]. Oxford: Radcliffe Medical Press; 1998 [cited 2017 Oct 28]. Reference Source

26. Marshall R, Pomeroy E: WorkbookFinalPEM.xlsx. figshare. Dataset. 2019. http://www.doi.org/10.6084/m9.figshare.7940753.v1 


\section{Open Peer Review}

\section{Current Peer Review Status:}

\section{Version 1}

Reviewer Report 07 December 2020

https://doi.org/10.5256/f1000research.20449.r74794

(C) 2020 McNamara J. This is an open access peer review report distributed under the terms of the Creative Commons Attribution License, which permits unrestricted use, distribution, and reproduction in any medium, provided the original work is properly cited.

John McNamara

Department of Anaesthesiology, Cork University Hospital, University College Cork, Cork, Ireland

Thank you for the opportunity to review this interesting paper.

The use of online health information resources is clearly increasing and will continue to do so. This point is well made by the authors, and appropriate references are well cited.

This research is timely, in an era when we are increasingly aware of the potential for spread of misinformation online. The medical profession has long been aware of the potential pitfalls of misguided internet searches for health information. It is interesting to determine the prominence of low quality information. The approach of using multiple internet search engines is pragmatic and makes the results of the article applicable. Perhaps inclusion of the term "anaesthesia", as well as "anaesthetic", in the search terms would have captured additional relevant websites.

Overall the article is well-written and easy to read, and describes a topical issue which is not frequently addressed by the medical profession, despite the potential for positive impact on the health of our patients.

Is the work clearly and accurately presented and does it cite the current literature? Yes

Is the study design appropriate and is the work technically sound?

Yes

Are sufficient details of methods and analysis provided to allow replication by others? Yes

If applicable, is the statistical analysis and its interpretation appropriate? Yes

Are all the source data underlying the results available to ensure full reproducibility? 
Yes

Are the conclusions drawn adequately supported by the results?

Yes

Competing Interests: No competing interests were disclosed.

Reviewer Expertise: Regional anaesthesia, Cardiac anaesthesia

I confirm that I have read this submission and believe that I have an appropriate level of expertise to confirm that it is of an acceptable scientific standard.

Reviewer Report 31 January 2020

https://doi.org/10.5256/f1000research.20449.r58795

(C) 2020 Wainwright T et al. This is an open access peer review report distributed under the terms of the Creative Commons Attribution License, which permits unrestricted use, distribution, and reproduction in any medium, provided the original work is properly cited.

\section{Thomas W Wainwright}

Orthopaedic Research Institute, Bournemouth University, Bournemouth, UK

\section{Louise Burgess}

Orthopaedic Research Institute, Bournemouth University, Bournemouth, UK

Thank you for the opportunity to review this well-written analysis of online patient education materials on anaesthesia for total hip and knee replacement.

We commend the authors for investigating this relatively under-researched but important topic.

Overall, they have presented a valuable addition to the literature-base. We do, however have the following suggestions which we believe would strengthen the contribution of this article to healthcare professionals looking to create or direct patients to relevant educational materials online.

1. Whilst DISCERN is an appropriate tool for assessing the quality of written information about treatment choices, we invite the authors to elaborate on the following points:

Questions 1-8 of the DISCERN tool addresses the reliability of the publication, and questions 9 to 15 focus on the specific details on the information on treatment choices. The final component of the DISCERN tool is an overall quality score. It may be valuable to the reader for the authors to present the results from each criterion of the DISCERN score (for example, sources of information, aims, relevance, support with shared-decision making etc.), or at least each section (reliability, treatment options, overall quality), so they have specific details on what needs improving in the future design of online patient education materials. 
Three of the top five scoring websites were of academic authorship. Is it possible for the authors to provide some specific examples from these websites which led to a "high-quality" DISCERN score? Demonstrating examples of exemplar education materials may guide healthcare professionals in the design of high-quality educational materials in the future.

The quality of each website was assessed by two authors using the DISCERN instrument. Were there any discrepancies or disagreement between the two authors whilst evaluating the websites with the DISCERN tool? How were these discrepancies resolved?

2. We commend the authors for conducting three, validated readability tests. The authors found the Information Standard NHS quality mark was associated with improved readability; however along with HONcode were not found to have a significant correlation with quality. We would be interested to know if the "written passages" selected for the readability tests were all taken from the same section of the websites included in this study to reduce variability.

3. Search engines: Were the searches conducted on browsers with an empty cache? If not choosing to include the first three pages of results only would likely create an element of selection bias, whereby the websites are ones familiar to the authors. Hence, the sample chosen in this study may not represent the search of a layperson.

4. Finally, we must acknowledge that the search for patient education materials was conducted in September 2017. As the content available to patients online is continuously changing, the results of this search have likely been updated, or replaced, with new materials. It may be useful to re-run the search, so that the published results are as relevant as possible to current practice.

Is the work clearly and accurately presented and does it cite the current literature? Yes

Is the study design appropriate and is the work technically sound?

Yes

Are sufficient details of methods and analysis provided to allow replication by others? Partly

If applicable, is the statistical analysis and its interpretation appropriate? Yes

Are all the source data underlying the results available to ensure full reproducibility? Partly

Are the conclusions drawn adequately supported by the results?

Yes

Competing Interests: No competing interests were disclosed.

Reviewer Expertise: orthopaedic surgery, physiotherapy, rehabilitation, enhanced recovery after surgery, quality improvement 
We confirm that we have read this submission and believe that we have an appropriate level of expertise to confirm that it is of an acceptable scientific standard.

Author Response ( ) 01 Mar 2020

Mark Johnson, University College Dublin, Dublin, Ireland

Thank you Thomas and Louise for your time and effort in reviewing this paper.

Competing Interests: I am an author of this paper.

The benefits of publishing with F1000Research:

- Your article is published within days, with no editorial bias

- You can publish traditional articles, null/negative results, case reports, data notes and more

- The peer review process is transparent and collaborative

- Your article is indexed in PubMed after passing peer review

- Dedicated customer support at every stage

For pre-submission enquiries, contact research@f1000.com 